\title{
Serotonergic Neurosecretory Synapse Targeting Is Controlled by Netrin-Releasing Guidepost Neurons in Caenorhabditis elegans
}

\author{
Jessica C. Nelson and Daniel A. Colón-Ramos \\ Program in Cellular Neuroscience, Neurodegeneration, and Repair, Department of Cell Biology, Yale University School of Medicine, New Haven, \\ Connecticut 06536-0812
}

\begin{abstract}
Neurosecretory release sites lack distinct postsynaptic partners, yet target to specific circuits. This targeting specificity regulates local release of neurotransmitters and modulation of adjacent circuits. How neurosecretory release sites target to specific regions is not understood. Here we identify a molecular mechanism that governs the spatial specificity of extrasynaptic neurosecretory terminal (ENT) formation in the serotonergic neurosecretory-motor (NSM) neurons of Caenorhabditis elegans. We show that postembryonic arborization and neurosecretory terminal targeting of the C. elegans NSM neuron is dependent on the Netrin receptor UNC-40/DCC. We observe that UNC-40 localizes to specific neurosecretory terminals at the time of axon arbor formation. This localization is dependent on UNC-6/Netrin, which is expressed by nerve ring neurons that act as guideposts to instruct local arbor and release site formation. We find that both UNC-34/Enabled and MIG-10/Lamellipodin are required downstream of UNC-40 to link the sites of ENT formation to nascent axon arbor extensions. Our findings provide a molecular link between release site development and axon arborization and introduce a novel mechanism that governs the spatial specificity of serotonergic ENTs in vivo.
\end{abstract}

\section{Introduction}

Neurons can communicate through both junctional and nonjunctional presynaptic specializations. The relative frequencies of these two modes of neurotransmission vary between brain regions, but nonjunctional release sites (also called neurosecretory terminals) are particularly common among monoaminergic neurons (Descarries et al., 1990; Descarries and Mechawar, 2000; Chase et al., 2004; Fuxe et al., 2010; Parent et al., 2010; Jafari et al., 2011). These nonjunctional release sites lack distinct postsynaptic partners to encourage presynaptic maturation. Nonetheless, neuroanatomical studies have revealed that neurons elaborate arbors containing extrasynaptic neurosecretory terminals (ENTs) onto specific targets (Lidov and Molliver, 1982; Descarries et al., 1990; Voutsinos et al., 1994).

Received July 19, 2012; revised 0ct. 31, 2012; accepted Nov. 9, 2012.

Author contributions: J.C.N. and D.A.C.-R. designed research; J.C.N. performed research; J.C.N. and D.A.C.-R. analyzed data; J.C.N. and D.A.C.-R. wrote the paper.

This work was funded by National Institutes of Health Grants R01 NS076558 and R00 NS057931, a March of Dimes research grant, fellowships from the Klingenstein Foundation, and the Alfred P. Sloan Foundation (all to D.A.C.-R.) and Interdepartmental Neuroscience Program Training Grant 5 T32 NS 41228 (J.C.N.). We thank Y. Goshima, K. Shen, M. Koelle, and the Caenorhabditis Genetic Center for strains and reagents. We acknowledge www.wormimage.org for making available the C. elegans EM images. We thank the Hall laboratory for producing www.wormimage.org and D. Hall for his expertise and aid in analyzing and annotating EM sections. We also acknowledge the work of D. Albertson and M. Anness in annotating the EM prints and microscopist N. Thomson for obtaining images. We thank Z. Altun (www.wormatlas.org) for the NSM diagram used in Figures 1 and 7. We also thank C. Gao, J. Belina, E. Strittmatter, and G. Chatterjee for technical assistance and M. Hammarlund, C. Smith, M. Koelle, K. Shen, and members of the Colón-Ramos laboratory for discussion and sharing of advice.

Correspondence should be addressed to Dr.Daniel A. Colón-Ramos, Department of Cell Biology, Yale Program in Cellular Neuroscience, Neurodegeneration, and Repair, Yale University School of Medicine, 295 Congress Avenue, BCMM 436B, New Haven, CT 06510. E-mail: daniel.colon-ramos@yale.edu.

DOI:10.1523/JNEUROSCI.3471-12.2012

Copyright $\odot 2012$ the authors $\quad 0270-6474 / 12 / 321366-11 \$ 15.00 / 0$
The precise targeting of these extrasynaptic release sites is crucial for their roles in locally modulating the responses of other neurons to junctional inputs. Across phyla, these extrasynaptic signals modulate vital functions, such as locomotion and arousal, as well as responses to salient or rewarding stimuli, such as food (Sawin et al., 2000; Chase et al., 2004; Fuxe et al., 2010). The physiological importance of achieving precise targeting of ENTs is perhaps best reflected by the fact that disruption in these systems is associated with a broad range of disorders, from drug addiction to movement disorders (Fuxe et al., 2010). Still, how target specificity arises for these neurosecretory terminals that lack postsynaptic partners is not understood.

The existence of nonjunctional release sites is conserved in the nematode Caenorhabditis elegans. For instance, both dopaminergic and serotonergic neurons in C. elegans are capable of communicating through nonjunctional terminals (Chase et al., 2004; Jafari et al., 2011). In particular, the main serotonergic neuron in C. elegans [neurosecretory-motor (NSM) neuron] extends axonal arbors decorated with ENTs onto specific target regions (Albertson and Thomson, 1976; Axäng et al., 2008; Jafari et al., 2011). The C. elegans NSM neuron provides an opportunity to examine targeted arborization and neurosecretory release site formation, because we can interrogate these conserved processes in vivo and with single-cell resolution.

Here we took advantage of the facile genetics of the C. elegans system to conduct an unbiased screen to identify the molecular mechanism that governs the spatial specificity of ENT formation. We observe that postembryonic arborization is dependent on the Netrin receptor UNC-40/DCC, which localizes to specific neurosecretory terminals at the time of axon arbor formation. This 
localization is dependent on UNC-6/Netrin, which is expressed by nerve ring neurons that act as guideposts to instruct local arbor and neurosecretory terminal formation. Our findings provide a molecular link between neurosecretory release site development and axon arborization and introduce a novel mechanism that governs the spatial specificity of ENTs in vivo.

\section{Materials and Methods}

Strains and genetics. Worms were raised on nematode growth media plates at $20^{\circ} \mathrm{C}$ using OP50 Escherichia coli as a food source. N2 Bristol was used as the wild-type (WT) reference strain. The following mutant strains were obtained through the Caenorhabditis Genetics Center: unc-40(e271)I, unc-6(ev400)X, sax-3(ky123)X, zdIs13 [tph-1p::gfp], jsIs682[rab-3p::gfp::rab-3]; rab-3(ju49), unc-34(e566), unc-34(lq17), mig-10(ct41), ced-5(tm1950), unc-73(e936), ced-10(n3246), mig-2(mu28), rac-2(ok326), unc-104(e1265), madd-2(ok2226), madd-2(ky602), and madd$4(o k 2854)$. The $u n c-40(e 271)$ mutation is a null allele. The nucleotide polymorphism is c7968t and results in an R824* in the ectodomain (Peter Roy, personal communication). ghIs9 [unc-6p::venus::unc-6]; unc-6(ev400) was received from Yoshio Goshima (Yokohama City University, Yokohama, Japan) (Asakura et al., 2010). vsIs45 [tph-1p::gfp] was a gift from Michael Koelle (Yale University, New Haven, CT). "Three-day-old adults" are $1 \mathrm{~d}$ post-L4 animals. "Four-day-old adults" are $2 \mathrm{~d}$ post-L4 animals. All analyses were performed using hermaphrodite nematodes. Unless otherwise indicated, "adult" nematodes are 3-d-old adults.

Molecular biology and transgenic lines. Expression clones were made in the pSM vector, a derivative of pPD49.26 (A. Fire, Stanford University, Palo Alto, CA) with extra cloning sites (S. McCarroll and C. I. Bargmann, unpublished data). The plasmids and transgenic strains $(0.5-30 \mathrm{ng} / \mu \mathrm{l})$ were generated using standard techniques (Mello and Fire, 1995) and coinjected with markers unc-122p::gfp or unc-122p::dsRed, olaIs1 [tph-1p::mCherry; tph-1p::cat-1::gfp], olaEx292 [tph-1p::mCherry], olaEx390 [unc-40p::unc-40; tph-1p::mCherry], olaEx188 [tph-1p::unc-40], olaEx799 [tph-1p::unc-40::gfp; tph-1p::mCherry], olaEx570 [tph-1p::unc-40::gfp; tph-1p::mCherry::rab-3], olaEx861 [unc-6p::gfp; tph-1p::mCherry], olaEx192 [tph-1p::unc-34a], olaEx253 [tph-1p::mig-10a], olaEx1113 [tph-1p::snb-1::yfp; tph-1p::mCherry::rab-3]; olaEx1117 [tph-1p::gfp]; olaEx1106 [tph-1p::gfp::syd-2; tph-1p::mCherry::rab-3].

Detailed subcloning information will be provided on request.

Ethyl methanesulfonate mutagenesis and mutant cloning. unc-40(ola53) was isolated from a visual forward genetic screen designed to identify mutants with abnormal arborization in NSM. vsIs45 animals were mutagenized with ethyl methanesulfonate (EMS) as described previously (Brenner, 1974). Complementation tests were performed by generating ola53/unc-40(e271) trans-heterozygotes. The ola53 allele failed to complement unc-40(e271). The ola53 allele was sequenced using Sanger sequencing techniques, which revealed a single $\mathrm{C}$-to- $\mathrm{T}$ nucleotide substitution in exon 3 of $u n c-40$ that results in a nonsense mutation R77*.

Fluorescence microscopy and confocal image acquisition and analysis. Images of fluorescently tagged fusion proteins were captured in live $C$. elegans nematodes using a $60 \times$ CFI Plan Apo VC, numerical aperture 1.4, oil-immersion objective on an UltraView VoX spinning-disc confocal microscope (PerkinElmer Life and Analytical Sciences). Worms were immobilized using $10 \mathrm{~mm}$ levamisole (Sigma) and oriented anterior to the left and dorsal up. Images were analyzed using Volocity software (Improvision). Ratiometric images were generated using Volocity software as a ratio between CAT-1::GFP signal and cytosolic mCherry signal.

Cell autonomy and mutant rescue. The ola53 mutant phenotype was rescued using an unc-40 mini-gene construct as described previously (Colón-Ramos et al., 2007). Cell-specific rescue was achieved by expressing unc-40 cDNA under the control of the $t p h-1$ promoter (Sze et al., 2002).

Quantification. Quantification of the NSM arborization pattern was performed using two criteria to denote WT phenotype. These include (1) enrichment of axon arbors within the region of NSM neurite that traverses the middle of the pharyngeal isthmus between the first and second pharyngeal bulbs. (2) When quantified by examining confocal micrographs, average arbor length for a given animal is $3 \mu \mathrm{m}$ in length or more, as measured from the intersection from the main neurite to the arbor tip. These two criteria were based on the WT phenotype as characterized by published studies (Axäng et al., 2008). Mutant phenotypes and rescue were assessed using an UltraView VoX spinning-disc confocal microscope and a Leica DM5000 B microscope. Ventral guidance was scored as WT if the neurite reached the second pharyngeal bulb, and dorsal guidance was scored as WT if the neurite terminated halfway between the first and second pharyngeal bulbs.

ENT quantifications were performed by generating line scans of CAT-1::GFP along the main NSM neurite. These line scan plots were then given a score of 0 or 1 describing the degree of ENT clustering, with 1 describing WT levels of ENT clustering and 0 describing diffuse localization. These data were then averaged for each genotype.

Quantification of the relationship between arbor position and shaft ENT position was performed by inspecting confocal micrographs of animals coexpressing CAT-1::GFP and cytosolic mCherry. Arbors were scored as associated with a shaft ENT if CAT-1::GFP puncta were observed at the intersection between the axon arbor and the main neurite shaft. A total of 70 arbors were scored across 13 animals, and $78 \%$ of arbors were determined to be associated with a shaft ENT, with a $95 \%$ confidence interval extending from 66.4 to $85.7 \%$.

Quantification of UNC-40::GFP localization relative to mCherry:: RAB-3 puncta was performed by visually inspecting confocal micrographs of animals simultaneously expressing UNC-40::GFP and mCherry::RAB-3. UNC-40::GFP puncta were scored as partially overlapping with mCherry::RAB-3 clusters if GFP and mCherry signal was continuous (i.e., no gaps were visible). A total of $78.3 \%$ of UNC-40::GFP clusters partially overlap with mCherry: RAB-3 clusters (with a $95 \%$ confidence interval that extends from 57.7 to $90.8 \%$ of UNC-40::GFP clusters partially overlapping with mCherry::RAB-3 clusters). Of the $21.7 \%$ of clusters that did not partially overlap with mCherry::RAB-3 clusters, all were localized to axon arbors and averaged a distance of $1.20 \mu \mathrm{m}$ from the nearest shaft RAB-3 cluster ( $n=5$ animals).

EM analyses. EM micrographs were obtained from www.wormimage. org. The EM micrographs presented were obtained from the pharyngeal isthmus set from animal N2W, which was imaged by microscopist Nichol Thomson (MRC, Cambridge, UK), annotated by Donna Albertson and Marilyn Anness (MRC, Cambridge, UK), and curated by the laboratory of David Hall at Albert Einstein College of Medicine (New York, NY) through their repository (www.wormimage.org).

To determine the presence of arbors and release sites in EM micrographs, we analyzed EM micrograph series for three animals: JSA, N2W, and $\mathrm{N} 2 \mathrm{~T}$. We examined serial sections obtained in the anatomical region extending from the posterior part of the first pharyngeal bulb to the anterior part of the second pharyngeal bulb. In the case of animal N2W, from which micrographs in Figure 1, $A$ and $B$, were obtained, this region included images 136-575. Images were inspected for arbor-like extensions continuous with the main NSM neurite and bounded by a visible lipid bilayer. Arbors were then inspected for the presence of synaptic vesicle accumulations and dense projections as described previously and with the assistance of David Hall (White et al., 1986). The micrographs presented in Figure 1, $A$ and $B$, are representative of other arbors that were also visualized in micrographs obtained for this region in animals JSA, N2W, and N2T.

Statistical analyses. $p$ values for categorical rescue data were calculated using Fisher's exact test. Error bars for categorical data were calculated using 95\% confidence intervals. Statistical significance for UNC-6expressing guidepost neuron relationship to NSM arbors was determined using the $\chi^{2}$ test. For continuous data, $p$ values were calculated by performing $t$ tests. Error bars for continuous data were calculated using SEM.

\section{Results \\ NSM exhibits stereotyped postembryonic arborization and ENT formation}

We generated single-cell fluorescent markers to simultaneously visualize NSM morphology and ENT development. The bilaterally symmetrical NSMs extend their neurites during embryogen- 

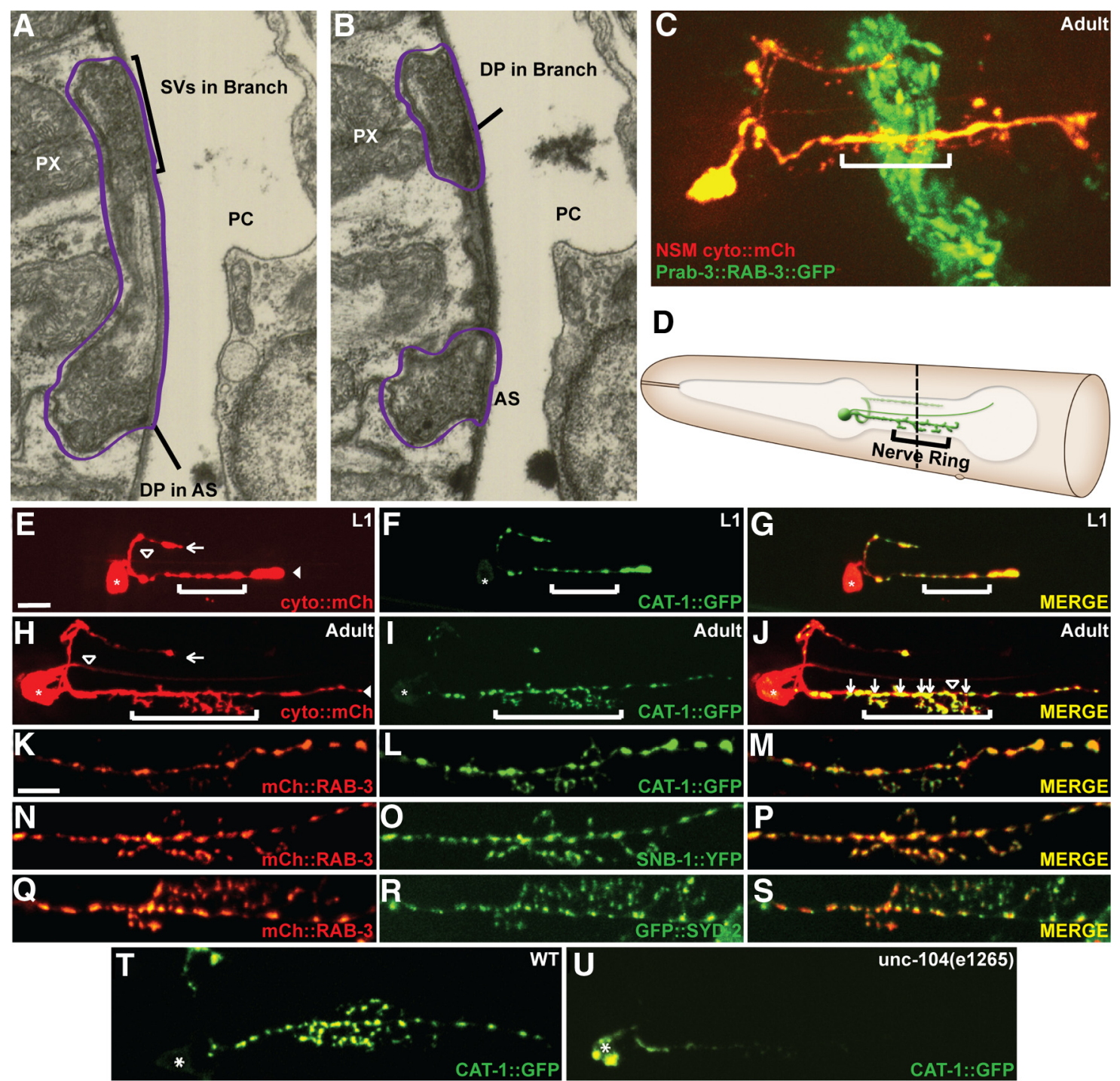

Figure 1. The serotonergic NSM neuron forms ENT-containing axon arbors in a specific neuroanatomical coordinate. $A, B$, Electron micrograph sequence of cross-sections through the pharynx of worm N2W (www.wormimage.org). NSM (outlined in purple) forms an axon arbor (vertical projection) at the edge of the pharynx (PX) near the pseudocoelom (clear space annotated as PC). In $A$, synaptic vesicle clusters (SV) are visible at the base of the arbor (line) and in the tip of the arbor (bracket). A dense projection (DP) onto the pseudocoelom is visible in the base of the arbor (line). In $\boldsymbol{B}$, the arbor has turned posteriorly and appears discontinuous from the main axon shaft (AS). Synaptic vesicle clusters are still visible in the main NSM axon shaft and in the tip of the arbor. A dense projection (DP) is also visible in the tip of the branch (line), facing the pseudocoelom (PC). C, Simultaneous visualization of NSM and the nematode nerve ring. NSM was imaged by expressing cytosolic mCherry using the tph-1 promoter (Sze et al., 2002), and the nerve ring was imaged by expressing transgene rab-3p:::AAB-3::GFP. Note that arbors form in regions adjacent to the nerve ring (brackets). D, Schematic diagram of NSM neuron (modified image adapted from www.wormatlas.org with permission). As shown in the schematic, arbors form in the isthmus region of the pharynx, proximal to the nerve ring. Dashed line indicates the approximate location of the EM cross-sections shown in $\boldsymbol{A}$ and $\boldsymbol{B}$. E-G, NSM in the L1 nematode. E, Cytosolic mCherry expressed cell specifically in NSM. Note the absence of arbors in the nerve ring region (bracket). Arrow marks dorsal neurite, open arrowhead marks proprioceptive dendrite, and filled arrowhead marks ventral neurite. $\boldsymbol{F}$, Distribution of serotonergic vesicle clusters. $\mathbf{G}$, Merge. $\boldsymbol{H}-\boldsymbol{J}$, NSM in the 3-d-old adult nematode. $\boldsymbol{H}$, As in $\boldsymbol{E}$ for adult. $\boldsymbol{I}$, As in $\boldsymbol{F}$, for adult. Note the presence of vesicle clusters in the terminal arbors (brackets).J, Merge. Arrows indicate mature arbors with synaptic vesicle clusters at their bases. Open arrowhead indicates mature arbor lacking synaptic vesicle cluster at the base. A total of $78 \%$ of axon arbors are associated with synaptic vesicle clusters at their base ( $n=70$ with a $95 \%$ confidence interval extending from 66.4 to $85.7 \%) . K-M$, Localization of CAT-1::GFP $(\boldsymbol{L})$ and $\mathrm{mCherry}: \mathrm{RAB}-3$ $(\boldsymbol{K})$ in NSM, with merge in $\boldsymbol{M} . \boldsymbol{N}-\boldsymbol{P}$, Localization of SNB-1::YFP $(\boldsymbol{O})$ and mCherry::RAB-3 $(\boldsymbol{N})$ in NSM, with merge in $\boldsymbol{P}$. $\boldsymbol{Q}-\boldsymbol{S}$, Localization of GFP::SYD-2 $(\boldsymbol{R})$ and $\mathrm{mCherry}::$ RAB-3 $(\boldsymbol{Q})$ in NSM, with merge in S. T, U, CAT-1:GFP localization in WT (T) or unc-104(e1265) mutant animals (U). In all images, anterior is oriented to the left and dorsal is oriented up, as in the diagram (D). Bracket represents the expected position of the nerve ring as it circumvents the pharyngeal isthmus, and asterisk denotes position of the NSM cell body. Scale bars (in $\boldsymbol{E}$ ): $\boldsymbol{E}-\boldsymbol{J}, 5 \mu \mathrm{m}$; (in $\boldsymbol{K}) \boldsymbol{C}, \boldsymbol{K}-\boldsymbol{U}, 5 \mu \mathrm{m}$.

esis (data not shown) (Axäng et al., 2008). As reported previously, the main neurite bifurcates just posterior to the cell body, forming two axons and one sensory dendrite (Fig. $1 D, E, H$; Albertson and Thomson, 1976; Axäng et al., 2008). The guidance of these neurites is completed during embryogenesis before the animal hatches (Fig. 1E; Axäng et al., 2008). Days later, after the animal has hatched and completed early larval stages, we observe that the ventral neurite arborizes within a well-defined neuroanatomical coordinate that corresponds to the location of the nematode nerve ring (Fig. 1C, D, H; Axäng et al., 2008). These findings are consistent with previous reports and suggest a temporal uncoupling of the processes of axon guidance and axon arborization in NSM, with arborization occurring days after axon guidance has terminated (Axäng et al., 2008).

Interestingly, the main serotonergic neuron in the parasitic nematode Ascaris suum, which is also called NSM, also arborizes over the nerve ring region. A. suum NSM neurons differ from $C$. elegans neurons in terms of both soma position and guidance. $A$. suum NSM cell bodies are positioned posterior to the nerve ring, unlike the C. elegans NSM, which is positioned anteriorly. As a 
result, A. suum NSMs guide anteriorly toward the nerve ring, whereas $C$. elegans NSMs guide posteriorly to reach the nerve ring. Despite these differences, in both species these neurosecretory neurons arborize specifically over the nerve ring (Johnson et al., 1996). This conserved relationship suggests that targeting mechanisms exist in nematodes to specify neurosecretory neuron arborization over the nerve ring.

Axon arbors of NSM are highly varicose and have been suggested to contain release sites (Axäng et al., 2008). To determine whether these axon arbors form synaptic-like release sites, we first inspected serial EM micrographs of the pharyngeal region from the C. elegans EM repository WormImage (see Materials and Methods). In particular, we examined EM sections taken from the center portion of the pharyngeal isthmus, in which axon arbors typically form (Fig. 1D, dashed line in diagram). As reported previously, we observed that NSM extends axon arbors adjacent to the basement membrane of the pharynx (Fig. 1A, $B$; Axäng et al., 2008). Furthermore, we observe dense projections and synaptic vesicles in both the axon arbors and the main shaft of the NSM neurite (Fig. $1 A, B$ ). Our observations indicate that the NSM neuron can form release sites in both the main axon shaft and the axon arbors.

To image these release sites in vivo, we expressed proteins that localize to synaptic vesicles (RAB-3 and SNB-1) or active zones (SYD-2) cell specifically in NSM. Consistent with the EM data, we observed RAB-3, SNB-1, and SYD-2 colocalized in a punctate pattern in both the main axon shaft and axon arbors (Fig. $1 K-S$ ). Importantly, we observed that the vesicular serotonin transporter CAT-1 (Duerr et al., 1999) colocalizes with RAB-3, suggesting that the observed release sites correspond to serotonergic vesicle clusters (Fig. $1 K-M$ ). We also observed that CAT-1:GFP localization to the arbors was dependent on UNC-104/kinesin (Fig. $1 T, U)$. Together, our findings indicate that synaptic vesicles are transported to and cluster at release sites in the arbors of NSM.

Using these in vivo markers, we next examined the developmental dynamics of the ENTs in NSM. Examination of ENT development across hundreds of individual animals demonstrated that, although the number, shape, and pattern of arbors varies between individuals, where and when arbors and ENTs form is highly stereotyped across animals $(n>500$ animals; Fig. $1 E-J)$.

Interestingly, we observe a spatial correlation between the position of the vesicle clusters and axon arbor branch points. Although vesicle clusters, particularly those in the extreme distal and proximal portions of the neurite, are not all associated with arbors, the majority of arbors are associated with vesicle clusters (Fig. 1J, arrows). Specifically, 78\% of axon arbors contain synaptic vesicle clusters at their base $(n=70)$ (Fig. $1 J$; for quantification strategy and variance, see Materials and Methods). These in vivo data are consistent with EM micrographs that reveal release sites at the base of axon arbors (Fig. 1A). A correlation between presynaptic release sites and arbor branch points has also been observed in vertebrates, in which it has been suggested that release site positions could instruct the emergence of branches and arbors (Alsina et al., 2001; Javaherian and Cline, 2005; Ruthazer et al., 2006).

In summary, our markers allow us to visualize arborization and ENT development with single-cell resolution and in vivo. Consistent with previous reports, we observe that NSM forms neurosecretory release sites in the arbors directly apposed to the basement membrane of the pharynx, proximal to the nerve ring (Axäng et al., 2008).

\section{UNC-40 instructs axon arborization and synaptic vesicle clustering}

To identify molecular signals that regulate the precise targeting of serotonergic ENTs in vivo, we performed a forward genetic EMS screen. From this screen, we identified a mutant, ola53, with a highly penetrant defect in arbor and ENT formation. Specifically, ENT-containing arbors in ola53 animals are essentially absent from the nerve ring terminal field [Figs. $2 B, 3 C$; in WT, $95.5 \%$ of animals display ENT-containing arbors in the terminal field $(n=$ 22 animals), whereas in ola53 mutants, $4.3 \%$ of animals display arbors ( $n=47$ animals)]. This defect is not likely a developmental delay because we did not detect arbors in the target field even in 4-d-old adult mutants (Fig. 2, compare $C, D$ ).

We also observe that, in the mutant animals, vesicles within the ventral neurite fail to cluster properly. Instead, mutants display a more diffuse distribution of serotonin-containing vesicles along the length of the ventral neurite (Fig. $2 F-K$ ). Specifically, we observed that, although synapses are clustered in $85.0 \%$ of adult WT animals ( $n=20$ animals), they fail to cluster in $50.0 \%$ of mutants ( $n=22$ animals).

We then conducted genetic analyses to uncover the molecular lesion responsible for the ola53 mutant phenotype. Three lines of evidence indicate that ola53 is a novel allele of the canonical axon guidance receptor, unc-40/DCC. First, our novel mutant allele, ola53, phenocopies and fails to complement the canonical unc40(e271) allele (Fig. 3 A, C and data not shown). Second, sequencing of the unc- 40 genetic locus in ola53 mutants revealed an early stop codon in the $u n c-40$ gene (Fig. $2 E$ ). Third, axon arborization defects in ola53 mutant animals are rescued by an unc-40 minigene construct (data not shown). Together, our findings indicate that ola53 is an allele of $u n c-40$ and reveal a novel role for this receptor in promoting local development of ENTs in serotonergic neurons.

UNC-40/DCC is an UNC-6/Netrin receptor and is best known for its role in axon guidance (Chan et al., 1996; KeinoMasu et al., 1996). In unc-40(ola53) animals and in animals carrying the canonical null allele $u n c-40(e 271)$, we observe outgrowth defects of the dorsal neurite as reported previously (Axäng et al., 2008). However, the ventral axons that bear the synaptic vesicle-containing arbors display normal guidance and outgrowth (Fig. $2 B$; no significant difference in length between WT and unc-40 ventral neurites was observed; data not shown). Thus, the observed requirement for local development of ENTs is not a result of ventral axon guidance defects in NSM. These data are consistent with observations that axon guidance and axonal arborization are temporally uncoupled processes in NSM development (Axäng et al., 2008). Interestingly, a similar temporal uncoupling of axon guidance and terminal arborization has been observed for serotonergic neurons in the rat CNS, in which it has been suggested that these distinct developmental steps for vertebrate serotonergic neurons may depend on separate sets of factors (Jacobs and Azmitia, 1992).

\section{UNC-40 acts cell autonomously in NSM, in which it localizes to extrasynaptic release sites and instructs local axon arborization}

To identify where UNC-40 acts to instruct arborization and vesicle clustering, we first examined cell-specific rescue of unc40(e271) in NSM. To achieve this, we generated a transgene that expresses unc-40 cDNA using the cell-specific NSM promoter tph-1p (Sze et al., 2002). Expression of this transgene in unc$40(e 271)$ animals results in rescue of the $u n c-40(e 271)$ arboriza- 

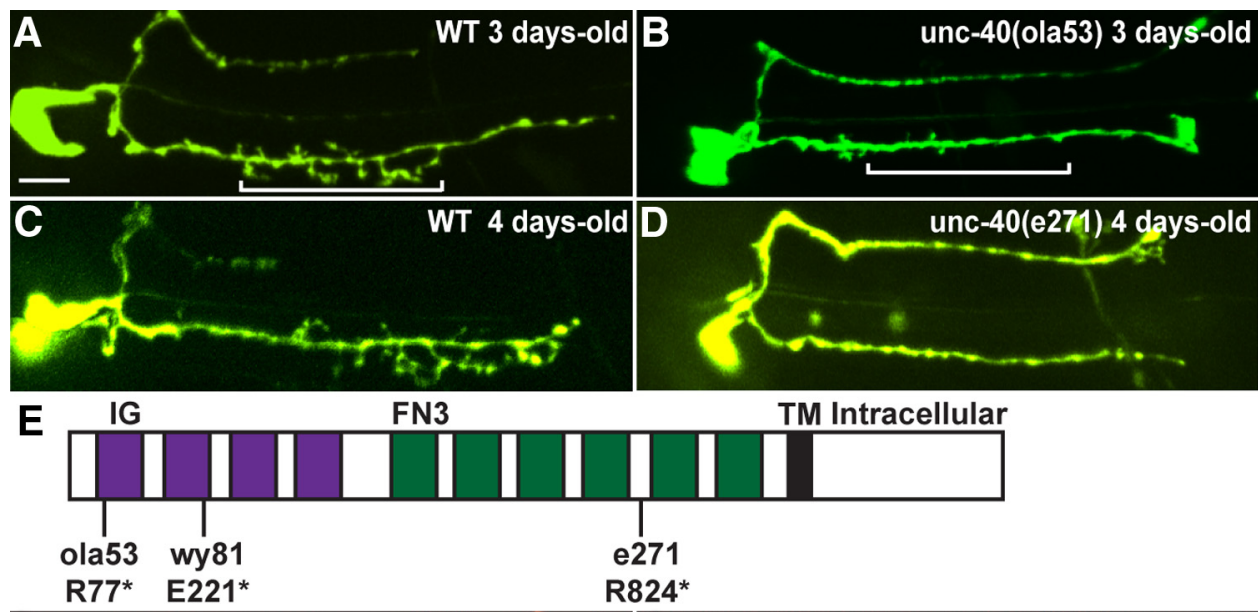

FN3

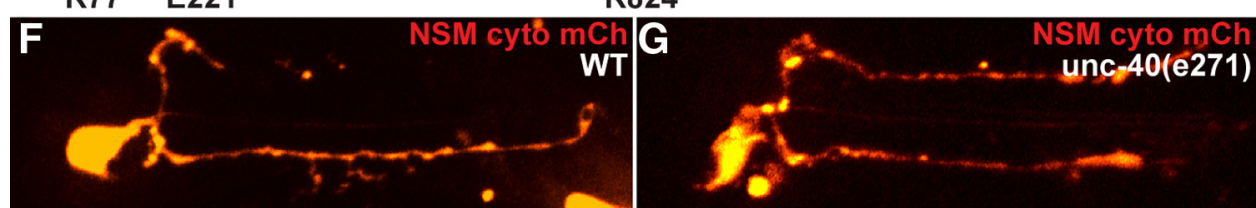

R824*
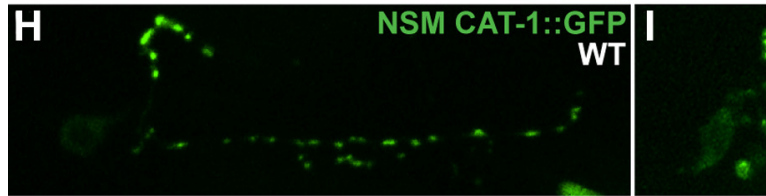

TM Intracellular
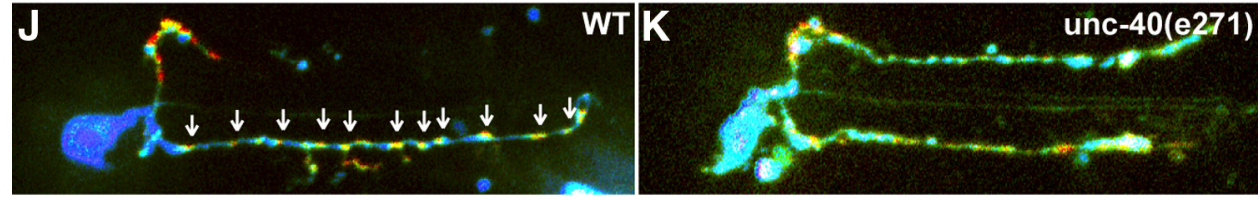

Figure 2. UNC-40 is required for terminal arbor formation and synaptic vesicle clustering in the NSM neuron. $A, B$, NSM neuron in adult nematodes visualized by cell-specific expression of GFP. $\boldsymbol{A}$, WT adult; note arbor length and position within nerve ring region (bracket). $\boldsymbol{B}$, unc-40(ola53) mutant adult. Note the absence of terminal arbors. $\boldsymbol{C}, \boldsymbol{D}$, As in $\boldsymbol{A}$ and $\boldsymbol{B}$ for 4-d-old adults. $\boldsymbol{E}, \mathrm{Schematic}$ diagram of the UNC-40 gene product with known alleles marked. unc-40(ola53) allele corresponds to a single C-to-T nucleotide substitution in exon 3 that results in a nonsense mutation R77*. The unc-40(ola53) stop codon is closer to the N terminus than other putative null alleles, unc-40(wy81) and unc-40(e271) (Colón-Ramos et al., 2007). F, G, NSM neuron in adult nematodes visualized by cell-specific expression of mCherry. Note that unc-40(e271) mutants phenocopy unc-40(ola53). H, I, NSM ENTs visualized with CAT-1::GFP. Note the diffuse appearance of synaptic vesicles in unc-40(e271) mutants $(\boldsymbol{I})$. $\boldsymbol{J}, \boldsymbol{K}$, Ratiometric images of NSM in which CAT-1::GFP signal is compared with cytosolic mCherry signal. Regions of high ratio between CAT-1::GFP and mCherry appear red, and regions of low ratio appear blue. Note regions of high ratio punctuated by regions of low ratio in the WT NSM, representing regions of tight serotonergic vesicle clustering (arrows) separated by nonsynaptic regions $(\boldsymbol{J})$. Note the relative absence of such individual puncta in unc-40(e271) and the presence of larger, diffuse accumulations of serotonergic vesicles $(\boldsymbol{K})$.
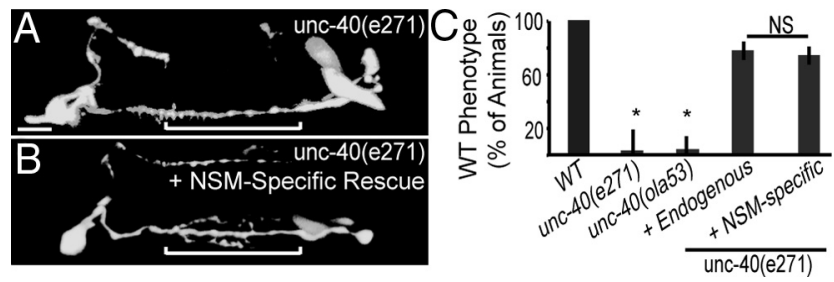

Figure 3. UNC-40 acts cell autonomously in the NSM neurons to instruct axon arborization. $\boldsymbol{A}, \boldsymbol{B}$, NSM neuron in adult nematodes visualized with cytosolic GFP. unc-40(e271) phenotype $(\boldsymbol{A})$ is rescued by NSM-specific expression of UNC-40 CDNA (B). C, Quantification of arborization phenotypes in the NSM neuron. Note that unc-40(e271) phenocopies ola53 and is similarly rescued by expression of UNC-40 under the endogenous regulatory elements or NSM-specific promoter. Error bars represent $95 \%$ confidence intervals. ${ }^{*} p<0.0001$.

tion defects (Fig. 3A-C), indicating that UNC-40 acts cell autonomously in NSM to instruct local arborization.

To understand how UNC-40 instructs local arborization and ENT formation, we visualized its subcellular localization in NSM by generating transgenic animals that express UNC-40::GFP cell specifically in NSM. We observed that UNC-40::GFP is diffusely localized in NSM neurites in larval stage 1 (L1) animals before arborization (Fig. $4 A-C, n>10$ ). Interestingly, we observed that, in L4 animals undergoing arborization, UNC-40 localizes to discrete puncta. UNC-40 subcellular localization during this stage corresponds to areas of the main NSM neurite adjacent to the nerve ring target field or to nascent arbors within the target field (Fig. $4 D-F, n>15$ ). We also observed that, in adult animals that have completed arborization, UNC-40 became diffusely localized (Fig. $4 G-I, n>10$ ). Our data indicate that UNC-40 subcellular localization is dynamically regulated during development and suggest that UNC-40 localizes to subcellular compartments within the nerve ring target region to instruct local arbor formation.

Given the requirement for UNC-40 in both vesicle clustering and local arbor formation in NSM, we hypothesized that UNC-40 might localize to specific release sites near the nerve ring to instruct local arborization. To examine this hypothesis, we simultaneously expressed UNC-40::GFP and the synaptic vesicle marker mCherry::RAB-3 and visualized the NSM neurons of L4 animals. We observed that all UNC-40::GFP puncta were localized in one of two places: clustered at the tips of nascent axon arbors or clustered adjacent to mCherry::RAB-3 puncta in the main axon shaft (Fig. $4 J-L^{\prime}$; for quantification strategy and vari- 

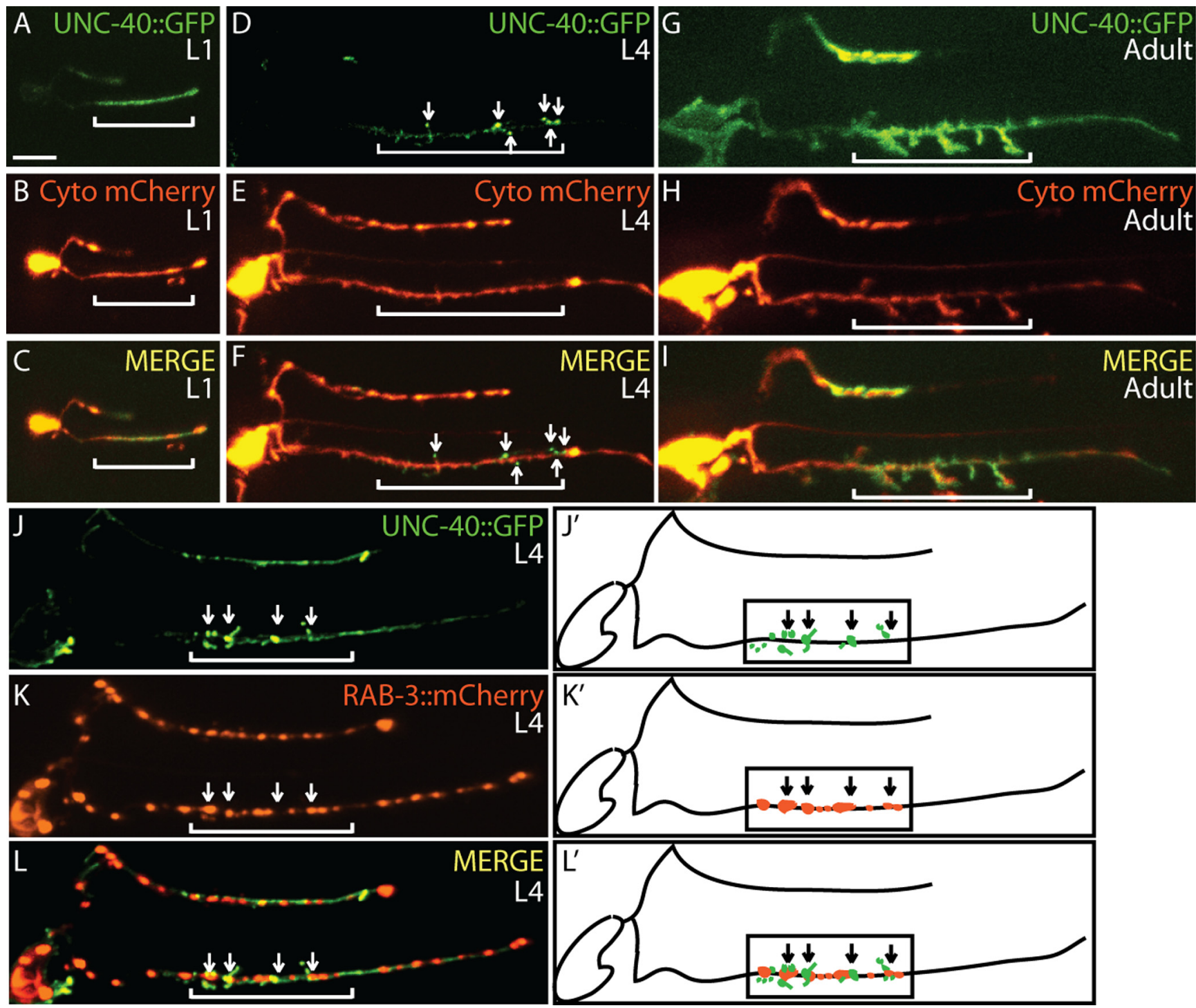

Figure 4. UNC-40 dynamically localizes to ENTs at the time of axon arborigenesis. A-I, Distribution of UNC-40::GFP and cytosolic mCherry in NSM in L1, L4, and adult animals. Note the enrichment of UNC-40::GFP at discrete puncta along the ventral neurite in $L 4$ animals, as arbors are beginning to form (arrows). $J$ - L, Simultaneous visualization of UNC-40::GFP and mCherry:::RAB-3 in an L4 animal. Note that not all vesicle clusters are associated with UNC-40. However, UNC-40 clusters are associated with vesicle clusters (arrows) at the nerve ring region (brackets). $J^{\prime}-L^{\prime}$, Schematic diagram of UNC-40 (green) localization relative to RAB-3 (red).

ance, see Materials and Methods). Our findings suggest that UNC-40 localizes to vesicle clusters in the main axon shaft, in which it then instructs the outgrowth of nascent arbors. This model is also consistent with the observation that a majority of axon arbors within the nerve ring terminal field have synaptic vesicle clusters at their bases.

Recent studies conducted in the vertebrate optic tectum demonstrate that Netrin promotes arbor outgrowth and presynaptic assembly at junctional synapses (Manitt et al., 2009). Although NSM release sites are morphologically distinct from junctional synapses, our findings now provide evidence that could help explain how the Netrin receptor UNC-40 links release sites to arborization. We observe that UNC-40 localizes to vesicle clusters and promotes the outgrowth of arbors adjacent to the release sites. It has been observed that presynaptic sites promote the formation of nascent branches in a number of developmental contexts (Alsina et al., 2001; Javaherian and Cline, 2005; Ruthazer et al., 2006; Manitt et al., 2009). Our observations now provide a molecular link that may explain the association between the position of release sites and axon arbor extension.

UNC-40-mediated ENT targeting is genetically separable from UNC-40-mediated branching and synaptogenesis Our observations regarding a requirement for UNC-40 in vesicle clustering and arborization in NSM are reminiscent of recently reported roles for the Netrin receptor in axon and dendrite branching and in the formation of junctional synapses (Manitt et al., 2009; Hao et al., 2010; Park et al., 2011; Smith et al., 2012; Stavoe and Colón-Ramos, 2012; Timofeev et al., 2012). To determine whether the molecular mechanisms underlying ENT targeting are shared with branching and synaptogenesis, we examined whether molecules required for branching and synaptogenesis downstream of UNC-40 in other neurons were also required for arborization in NSM.

We first examined the role of madd-2/trim-9, a tripartite motif protein that was shown recently to act in the UNC-40 pathway in 
axon branching (Hao et al., 2010). We observe that madd-2(ok2226) mutant animals display defective outgrowth of the ventral neurite of NSM, with one or more ventral neurites failing to extend in $80 \%$ of madd-2(ok2226) mutant animals $(n=$ $30)$. Because the arbor-containing ventral neurites do not develop correctly in madd-2(ok2226) mutant animals, we were unable to examine the arbors in this mutant background. However, our findings indicate that madd- 2 is required for extension of the ventral neurite and suggest that madd-2 is involved primarily in unc-40independent outgrowth events in NSM.

We next examined whether signaling molecules required for UNC-40-mediated synaptogenesis were also required for arborization in NSM. UNC-40 plays a conserved role in instructing presynaptic assembly of junctional synapses (ColónRamos et al., 2007; Manitt et al., 2009; Park et al., 2011). The molecular mechanisms required for UNC-40-mediated vesicle clustering at presynaptic sites were identified recently and shown to depend on the Rac GEF, CED-5/DOCK-180, and CED-10/ RAC1 (Stavoe and Colón-Ramos, 2012). To determine whether the mechanisms that underpin UNC-40-dependent synaptogenesis (in AIY interneuron) and UNC-40dependent arborization (in NSM) are shared, we examined NSM in ced5(tm1950) and ced-10(n3246) mutant animals. We observe that ced-5(tm1950) mutant animals display WT axon arborization in NSM ( $n>30$ animals), suggesting that it is not required for NSM axon arborization. For ced-10(n3246) mutant animals, we observe defective outgrowth of the ventral neurite of NSM, with one or more ventral neurites failing to extend in $>60 \%$ of ced-10(n3246) mutant animals $(n=27)$. This phenotype, which was similar to that observed for madd-2(ok2226) mutants, prevented us from examining the ced-10 requirement in arborization and suggested that ced-10, like madd-2, is involved in unc40-independent outgrowth events in NSM.

Together, our findings indicate that the molecular factors involved downstream of UNC-40 in presynaptic assembly and branching are either not required for NSM arborization (as in the case of ced-5) or play other roles in NSM ventral neurite outgrowth (as in the case of madd-2 and ced-10).

We then examined whether other downstream components of the Netrin pathway involved in guidance and cell migration could be required for NSM axon arborization. We first examined whether the Rac GEF unc-73/Trio or the Racs mig-2 and rac-2 were required for arborization in NSM (Zipkin et al., 1997; Lundquist et al., 2001). We observed that 64\% of unc-73(e936) mutants display a defect in axon arborization in NSM $(n=25$ animals), indicating that the Rac GEF $u n c-73$ is required for axon arborization in NSM. However, we did not observe a dramatic arborization phenotype for downstream Racs rac-2 or mig-2. rac2(ok326) mutants were not significantly different from WT $(n=$ 47), whereas mig-2(mu28) mutant animals display lowpenetrance arborization defects $[35 \%$ of $m i g-2(m u 28)$ animals display a defect in axon arborization, $n=40]$. These data indicate that the Rac pathway is at least partially required for NSM arborization.

UNC-40 exerts its functions through the cytoskeletal adaptor protein MIG-10/Lamellipodin and through UNC-34/Enabled (Gitai et al., 2003; Adler et al., 2006; Chang et al., 2006). We observe that mig-10(ct41) mutant animals display highly penetrant defects in axon arborization in NSM (Fig. 5E, $81.8 \%$ of animals display defective axon arborization, $n=44$ ) (Stavoe et al., 2012). We also observe a highly penetrant axon arborization 

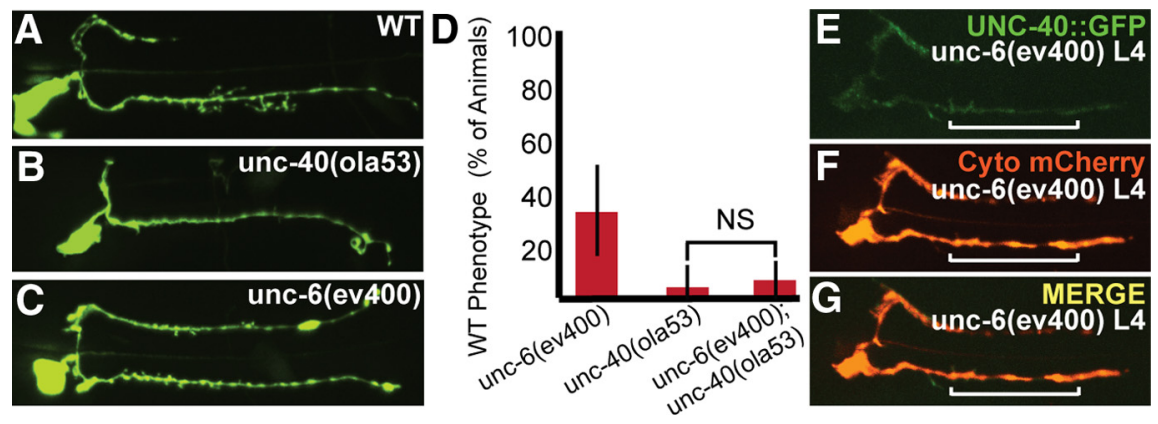

Figure 6. UNC-6 instructs UNC-40 localization and axon arbor formation. A-C, NSM neuron in adult nematodes visualized with cytosolic GFP. Note that unc-6(ev400) mutants (C) phenocopy unc-40(ola53) mutants (B). D, Quantification of the percentage of animals displaying WT arborization patterns in unc-6(ev400), in unc-40(ola53) and in unc-6(ev400); unc-40(ola53) double mutants. $E-G$, UNC-40::GFP (E) fails to localize to puncta in unc-6(ev400) L4 mutant animals.

defect in unc-34(e566) mutants (Fig. 5C, 92.3\% of animals display defective axon arborization, $n=26$ ). Cell-autonomy studies revealed that, like UNC-40, these two downstream molecules act cell autonomously in NSM to effect their function during arborization (Fig. 5D, $n=25, F, n=36$ ).

In vertebrates, the unc-34 homolog Ena/VASP directly interacts with the mig-10 homolog Lamellipodin during axonal morphogenesis (Krause et al., 2004; Michael et al., 2010). It has also been reported that $u n c-34$ and mig- 10 have non-overlapping and cooperative functions downstream of UNC-40 to mediate outgrowth (Chang et al., 2006). To understand how MIG-10 and UNC-34 act to instruct arborization, we generated mig-10(ct41); unc-34(lq17) double mutants. We observed that mig-10(ct41); unc-34(lq17) double mutants display an enhanced defect in axon arborization compared with mig-10(ct41) or unc-34(lq17) single mutants (Fig. $5 G, H, K$ ). These findings suggest that these two genes act cooperatively downstream of UNC-40 to instruct axon arborization in NSM. Consistent with this model, we observe that mig-10(ct41);unc-40(e271) and unc-34(lq17);unc-40(e271) doublemutants phenocopy the unc-40(e271) single mutants. Our findings indicate that axon arborization in NSM depends on signaling pathways that are different from those reported for branching and presynaptic assembly and more similar to those used to organize the actin cytoskeleton during outgrowth. Together with our previous findings, our data suggest that UNC-40 localizes to release sites in the shaft, in which it acts to organize the actin cytoskeleton to instruct axon arborization onto target regions.

\section{UNC-6-expressing guidepost neurons instruct local serotonergic axon arborization}

The local development of ENTs and the subcellular localization of UNC-40 suggest the existence of local signals that instruct these processes. UNC-40/DCC is a receptor for UNC-6/Netrin (Chan et al., 1996; Keino-Masu et al., 1996). Therefore, we next examined whether UNC-6/Netrin was required for arborization and ENT development in NSM.

We found that mutant animals lacking $u n c-6 /$ Netrin phenocopied unc-40 mutant animals (Fig. $6 A-D$ ). In $67.6 \%$ of unc6(ev400) animals $(n=34)$, axon arbors were absent from the nerve ring region. Consistent with Netrin acting as the ligand for UNC-40 in instructing arborization, we also observed that unc6(ev400);unc-40(ola53) double-mutant animals phenocopied the single mutants, with no enhancement in penetrance with respect to the downstream unc-40(ola53) phenotype [Fig. 6D, arbors absent in $95.7 \%$ of $u n c-40(e 271)$ mutants $(n=47)$; $93.1 \%$ in $u n c-$ 40(e271); unc-6(ev400) double mutants $(n=29)]$. We did not observe a dramatic phenotype in mutants lacking the UNC-40 ligand MADD-4 (data not shown) (Seetharaman et al., 2011).

We then examined whether UNC-6 was required for the subcellular localization of UNC-40::GFP in NSM. We observed that, in unc-6(ev400) mutant animals, UNC-40::GFP never clustered during the L4 stage, instead remaining diffusely localized throughout the development of the animal (Fig. $6 E-G, \mathrm{n}>15$ ). Our findings indicate that UNC-6/Netrin is required for UNC-40 clustering during NSM axon arborization and terminal ENT formation.

Consistent with UNC-6 acting as a local cue, we observed that broad expression of UNC-6/Netrin in unc-6(ev400) mutants using a heat-shock promoter did not result in rescue of the unc- 6 phenotype in NSM (data not shown). To examine whether UNC- 6 acts as a local cue, we first visualized the endogenous sites of UNC-6/Netrin expression during the time of NSM arborization. We achieved this by imaging L4 animals expressing an UNC-6::VENUS fusion protein under the unc- 6 endogenous regulatory elements (Asakura et al., 2010). As reported previously, we observed that the expression of UNC-6/Netrin persists postembryonically in few neurons (Wadsworth et al., 1996). Interestingly, we observed that UNC-6 expression persists in nerve ring neurons during the time of NSM arborization. Moreover, UNC-6/Netrin is transported to and clusters at the nerve ring (Fig. 7A-C; Wadsworth et al., 1996; Asakura et al., 2010). Careful inspection of UNC-6/Netrin clusters revealed that they are in close apposition to the sites of NSM arborization (Fig. $\left.7 C-C^{\prime \prime}, n>10\right)$.

NSM forms extrasynaptic release sites and does not have junctional synaptic partners at the nerve ring (Fig. 1A, B; Albertson and Thomson, 1976; Axäng et al., 2008). We hypothesized that these Netrin-expressing neurons, which are not postsynaptic partners to NSM, could serve as guideposts to direct localized arborization and ENT development near the nerve ring.

To examine this hypothesis, we altered the positions of the NSMs and Netrin-expressing neurons and assessed local arborization. We achieved this by visualizing Netrin-expressing neurons and NSM arbors in the sax-3(ky123) mutant background. SAX-3/ROBO is a guidance molecule required for axon pathfinding in many C. elegans neurons, including NSM (Axäng et al., 2008). Moreover, SAX-3/ROBO mutants display altered nerve ring positioning (Zallen et al., 1999). Therefore, in sax3 (ky123) mutants, the relative position of NSM with respect to the nerve ring is disrupted. Because the expressivity of the phenotype is variable, this provided an opportunity to evaluate animals in which NSM and the Netrin-expressing neurons intersected at aberrant coordinates in the animal or not at all. Analyses of the phenotypes revealed that proximity of the ventral NSM neurite to the Netrin-expressing neurons was associated with arborization (Fig. $7 D-E^{\prime} ; n=32$ animals). This occurred even when misguided NSM neurites were in proximity to misguided Netrin-expressing neurons outside the nerve ring and resulted in ectopic NSM arborization at the sites of proximity (such as the anterior procorpus; Fig. $7 E, E^{\prime}$ ). Conversely, if NSM neurites did not intersect with the Netrin-expressing neurons, arbors did not form (Fig. $7 D, n=20$ ). Together, our data indicate 
that UNC-6-expressing guidepost neurons instruct local serotonergic axon arborization and ENT targeting.

\section{Discussion}

The development of neurosecretory terminals onto specific target areas enables neurotransmitters and neuropeptides to exert local roles (Hornung, 2003; Vitalis and Parnavelas, 2003; Bonnin et al., 2007). Although the specificity of neurosecretory terminals is well documented in vertebrates and invertebrates, we do not yet understand how this precise architecture is specified (Descarries et al., 1990; Jacobs and Azmitia, 1992; Moukhles et al., 1997; Parent et al., 2010). Here we undertook an unbiased approach to identify the cellular and molecular mechanisms required for this process and uncovered a novel role for the unc-6/unc-40 signaling pathway in instructing local neurosecretory release site targeting. Our findings represent the first description of a mechanism underlying the spatial specificity of ENTs in vivo.

ENT development represents a unique challenge in synaptic specificity. Unlike junctional synapses, the neurosecretory release sites of NSM are unopposed by postsynaptic partners to encourage presynapse maturation and specificity. How neurosecretory release sites achieve specificity in targeting is therefore not known. Here we show that nerve ring neurons act as guideposts in specifying the positions of release sites in NSM. Guidepost neurons have been reported to coordinate the innervation of junctional synapses during embryonic development (McConnell et al., 1989; Ghosh et al., 1990; Del Río et al., 1997). We now identify that Netrin-expressing neurons in the nerve ring can serve a postembryonic role as guideposts specifying local neurosecretory release site formation.

Guidepost neurons instruct local arborization and release site formation of the NSMs through the expression of Netrin. Netrin is a chemotrophic factor best known for its role as a long-range cue instructing axon guidance and cell migrations (Hedgecock et al., 1990; Ishii et al., 1992; Serafini et al., 1994; Yee et al., 1999). Our work suggests that Netrin acts as a short-range signaling cue to specify the site of serotonergic arbor formation. This is perhaps best demonstrated by the fact that shifting the position of the guidepost neurons results in a shift in the position of the NSM axon arbors.

Previous studies have shown that Netrin can act as a shortrange signaling cue in several developmental contexts (Keleman and Dickson, 2001; Srinivasan et al., 2003; Baker et al., 2006; Brankatschk and Dickson, 2006). Recent work in C. elegans, Drosophila, and vertebrates has also uncovered roles for Netrin in synapse formation that are consistent with this chemotrophic factor acting as a short-range cue (Colón-Ramos et al., 2007; Manitt et al., 2009; Park et al., 2011; Timofeev et al., 2012). For example, a recent study in Xenopus describes a role for Netrin in encouraging presynaptic development of DCC-expressing retinal ganglion cells onto Netrin-expressing tectal neurons (Manitt et al., 2009). We now present evidence that Netrin acts as a short- range cue in nerve ring neurons that are not postsynaptic to the ENTs of NSM. Rather, these guideposts coordinate the local development of arbors and neurosecretory release sites proximal to the nerve ring target field.

Whether at long or short range, Netrin typically exerts its influence early in development (Hedgecock et al., 1990; Ishii et al., 1992; Serafini et al., 1994; Rajasekharan and Kennedy, 2009). However, studies of Netrin expression in both vertebrates and invertebrates have demonstrated that Netrin expression persists beyond embryonic development (Wadsworth et al., 1996; Livesey and Hunt, 1997; Manitt et al., 2001). Postembryonic roles for Netrin are not well understood, but it has been proposed that Netrin could play postdevelopmental roles in circuit maintenance and plasticity (Shatzmiller et al., 2008; Manitt et al., 2011). Our work identifies a novel postembryonic role for Netrin in specifying neurosecretory terminal differentiation in C. elegans.

We observe that Netrin is required for proper arborization of the NSM neuron at the specific target field proximal to the nerve ring. Our data suggest that UNC-40-mediated ENT targeting is genetically separable from UNC-40-mediated branching and synaptogenesis. For instance, the NSM neurite forms three major branches, and its ventral branch arborizes in the nerve ring region (Fig. 1). The processes of branch extension and arborization occur at different times in development. Interestingly, dorsal branch extension is also dependent on UNC-40, indicating that UNC-40 can play multifunctional roles within the same neuron to instruct different developmental events at various stages (Axäng et al., 2008). It appears that branching and arborization events are not only temporally uncoupled but are also molecu- 
larly uncoupled. For example, Netrin-dependent branching is dependent on the tripartite motif protein MADD-2 (Hao et al., 2010). We observe that, in NSM, madd-2 is primarily required for the outgrowth of the ventral neurite. unc- 40 does not play a major role in the outgrowth of the ventral neurite, suggesting that in NSM, madd- 2 pays an unc-40-independent role. Conversely, unc-34 and mig-10, are required for arborization, but mutants do not display obvious outgrowth defects of the ventral neurite. Together, our developmental and molecular data indicate that the process of arborization reported here and the process of branch outgrowth are distinct. Similarly, we observe that molecules required for Netrin-mediated presynaptic assembly are dispensable, or play minor roles, in NSM arborization.

Despite these important distinctions, unc-40-dependent outgrowth, branching, arborization, and presynaptic assembly all require specific patterns of UNC-40 subcellular localization (Adler et al., 2006; Hao et al., 2010; Park et al., 2011; Stavoe and Colón-Ramos, 2012). Indeed, in our system, Netrin exerts its role in axon arborization and terminal ENT formation by directing the localization of its receptor, UNC-40. The transient localization of UNC-40 to putative ENTs along the main neurite represents a link between the processes of axon arborization and the position of release sites. Consistent with this link, we observe a specific correlation between the positions of synaptic vesicle accumulations and axon arbor branch points. Such a correlation has been reported previously in vertebrate neurons (Alsina et al., 2001; Javaherian and Cline, 2005; Ruthazer et al., 2006; Manitt et al., 2009). Moreover, it was recently demonstrated that, in vertebrates, Netrin promotes arbor outgrowth and presynaptic assembly at junctional synapses (Manitt et al., 2009). Our study now supports a role for UNC-40 as the molecular link between the release sites and axon arborization. Specifically, our findings suggest that UNC-40 localizes to preexisting release sites in the shaft, in which it instructs outgrowth of arbors, which will then contain terminal ENTs.

In the absence of UNC-40, we observe defects in NSM in both local arborization and vesicle clustering. We hypothesize that underpinning both of these defects is the actin cytoskeleton. Consistent with this, we observe that unc-34/Enabled and mig-10/ Lamellipodin are required to instruct arborization. Both mig-10 and $u n c-34$ are known to regulate the actin cytoskeleton during axon outgrowth (Gitai et al., 2003; Chang et al., 2006; Drees and Gertler, 2008; Quinn and Wadsworth, 2008). mig-10 is also required to organize the actin cytoskeleton during synaptogenesis (Stavoe and Colón-Ramos, 2012). Therefore, our findings suggest that UNC-40 subcellular localization is required to organize the actin cytoskeleton to promote both vesicle clustering at release sites and axon arborization.

Evidence from vertebrate studies supports a role for the $\mathrm{Ne}$ trin pathway in the development of monoaminergic circuits. For example, studies in dopamine neurons suggest that the UNC-40 vertebrate homolog DCC regulates terminal arborization and synaptic organization of dopaminergic systems (Xu et al., 2010; Flores, 2011; Manitt et al., 2011). To our knowledge, although there is no evidence for Netrin regulating serotonergic release sites in vertebrates, Netrin and serotonin signaling pathways do intersect in several vertebrate contexts. First, high levels of DCC expression have been detected in developing embryonic murine serotonin neurons, suggesting a role for DCC during serotonin neurodevelopment in vertebrates (Wylie et al., 2010). Furthermore, it has been demonstrated that extrasynaptically released serotonin modifies the Netrin responses of axons originating from the posterior region of the dorsal thalamus, converting attrac- tion to repulsion, and demonstrating a developmental interplay between Netrin-responsive neurons and serotonin-expressing neurons (Bonnin et al., 2007). We now uncover a mechanism by which Netrin governs the spatial specificity of serotonergic ENTs in vivo. Given the evolutionary conservation of the described mechanisms, we speculate that our findings may represent a novel and conserved mechanism for the specification of neurosecretory release sites in vivo.

\section{References}

Adler CE, Fetter RD, Bargmann CI (2006) UNC-6/Netrin induces neuronal asymmetry and defines the site of axon formation. Nat Neurosci 9:511518. CrossRef Medline

Albertson DG, Thomson JN (1976) The pharynx of Caenorhabditis elegans. Philos Trans R Soc Lond B Biol Sci 275:299-325. CrossRef Medline

Alsina B, Vu T, Cohen-Cory S (2001) Visualizing synapse formation in arborizing optic axons in vivo: dynamics and modulation by BDNF. Nat Neurosci 4:1093-1101. CrossRef Medline

Asakura T, Waga N, Ogura K, Goshima Y (2010) Genes required for cellular UNC-6/netrin localization in Caenorhabditis elegans. Genetics 185:573-585. CrossRef Medline

Axäng C, Rauthan M, Hall DH, Pilon M (2008) Developmental genetics of the C. elegans pharyngeal neurons NSML and NSMR. BMC Dev Biol 8:38. CrossRef Medline

Baker KA, Moore SW, Jarjour AA, Kennedy TE (2006) When a diffusible axon guidance cue stops diffusing: roles for netrins in adhesion and morphogenesis. Curr Opin Neurobiol 16:529-534. CrossRef Medline

Bonnin A, Torii M, Wang L, Rakic P, Levitt P (2007) Serotonin modulates the response of embryonic thalamocortical axons to netrin-1. Nat Neurosci 10:588-597. CrossRef Medline

Brankatschk M, Dickson BJ (2006) Netrins guide Drosophila commissural axons at short range. Nat Neurosci 9:188-194. CrossRef Medline

Brenner S (1974) The genetics of Caenorhabditis elegans. Genetics 77:71-94. Medline

Chan SS, Zheng H, Su MW, Wilk R, Killeen MT, Hedgecock EM, Culotti JG (1996) UNC-40, a C. elegans homolog of DCC (Deleted in Colorectal Cancer), is required in motile cells responding to UNC-6 netrin cues. Cell 87:187-195. CrossRef Medline

Chang C, Adler CE, Krause M, Clark SG, Gertler FB, Tessier-Lavigne M, Bargmann CI (2006) MIG-10/lamellipodin and AGE-1/PI3K promote axon guidance and outgrowth in response to slit and netrin. Curr Biol 16:854-862. CrossRef Medline

Chase DL, Pepper JS, Koelle MR (2004) Mechanism of extrasynaptic dopamine signaling in Caenorhabditis elegans. Nat Neurosci 7:1096-1103. CrossRef Medline

Colón-Ramos DA, Margeta MA, Shen K (2007) Glia promote local synaptogenesis through UNC-6 (netrin) signaling in C. elegans. Science 318: 103-106. CrossRef Medline

Del Río JA, Heimrich B, Borrell V, Förster E, Drakew A, Alcántara S, Nakajima K, Miyata T, Ogawa M, Mikoshiba K, Derer P, Frotscher M, Soriano E (1997) A role for Cajal-Retzius cells and reelin in the development of hippocampal connections. Nature 385:70-74. CrossRef Medline

Descarries L, Mechawar N (2000) Ultrastructural evidence for diffuse transmission by monoamine and acetylcholine neurons of the central nervous system. Prog Brain Res 125:27-47. CrossRef Medline

Descarries L, Audet MA, Doucet G, Garcia S, Oleskevich S, Séguéla P, Soghomonian JJ, Watkins KC (1990) Morphology of central serotonin neurons. Brief review of quantified aspects of their distribution and ultrastructural relationships. Ann N Y Acad Sci 600:81-92. CrossRef Medline

Drees F, Gertler FB (2008) Ena/VASP: proteins at the tip of the nervous system. Curr Opin Neurobiol 18:53-59. CrossRef Medline

Duerr JS, Frisby DL, Gaskin J, Duke A, Asermely K, Huddleston D, Eiden LE, Rand JB (1999) The cat-1 gene of Caenorhabditis elegans encodes a vesicular monoamine transporter required for specific monoaminedependent behaviors. J Neurosci 19:72-84. Medline

Flores C (2011) Role of netrin-1 in the organization and function of the mesocorticolimbic dopamine system. J Psychiatry Neurosci 36:296-310. CrossRef Medline

Fuxe K, Dahlström AB, Jonsson G, Marcellino D, Guescini M, Dam M, Manger P, Agnati L (2010) The discovery of central monoamine neurons 
gave volume transmission to the wired brain. Prog Neurobiol 90:82-100. CrossRef Medline

Ghosh A, Antonini A, McConnell SK, Shatz CJ (1990) Requirement for subplate neurons in the formation of thalamocortical connections. Nature 347:179-181. CrossRef Medline

Gitai Z, Yu TW, Lundquist EA, Tessier-Lavigne M, Bargmann CI (2003) The netrin receptor UNC-40/DCC stimulates axon attraction and outgrowth through enabled and, in parallel, Rac and UNC-115/AbLIM. Neuron 37:53-65. CrossRef Medline

Hao JC, Adler CE, Mebane L, Gertler FB, Bargmann CI, Tessier-Lavigne M (2010) The tripartite motif protein MADD-2 functions with the receptor UNC-40 (DCC) in Netrin-mediated axon attraction and branching. Dev Cell 18:950-960. CrossRef Medline

Hedgecock EM, Culotti JG, Hall DH (1990) The unc-5, unc-6, and unc-40 genes guide circumferential migrations of pioneer axons and mesodermal cells on the epidermis in C. elegans. Neuron 4:61-85. CrossRef Medline

Hornung JP (2003) The human raphe nuclei and the serotonergic system. J Chem Neuroanat 26:331-343. CrossRef Medline

Ishii N, Wadsworth WG, Stern BD, Culotti JG, Hedgecock EM (1992) UNC-6, a laminin-related protein, guides cell and pioneer axon migrations in C. elegans. Neuron 9:873-881. CrossRef Medline

Jacobs BL, Azmitia EC (1992) Structure and function of the brain-serotonin system. Physiol Rev 72:165-229. Medline

Jafari G, Xie Y, Kullyev A, Liang B, Sze JY (2011) Regulation of extrasynaptic 5 -HT by serotonin reuptake transporter function in 5-HT-absorbing neurons underscores adaptation behavior in Caenorhabditis elegans. J Neurosci 31:8948-8957. CrossRef Medline

Javaherian A, Cline HT (2005) Coordinated motor neuron axon growth and neuromuscular synaptogenesis are promoted by CPG15 in vivo. Neuron 45:505-512. CrossRef Medline

Johnson CD, Reinitz CA, Sithigorngul P, Stretton AO (1996) Neuronal localization of serotonin in the nematode Ascaris suum. J Comp Neurol 367:352-360. CrossRef Medline

Keino-Masu K, Masu M, Hinck L, Leonardo ED, Chan SS, Culotti JG, TessierLavigne M (1996) Deleted in Colorectal Cancer (DCC) encodes a netrin receptor. Cell 87:175-185. CrossRef Medline

Keleman K, Dickson BJ (2001) Short- and long-range repulsion by the Drosophila Unc5 netrin receptor. Neuron 32:605-617. CrossRef Medline

Krause M, Leslie JD, Stewart M, Lafuente EM, Valderrama F, Jagannathan R, Strasser GA, Rubinson DA, Liu H, Way M, Yaffe MB, Boussiotis VA, Gertler FB (2004) Lamellipodin, an Ena/VASP ligand, is implicated in the regulation of lamellipodial dynamics. Dev Cell 7:571-583. CrossRef Medline

Lidov HG, Molliver ME (1982) An immunohistochemical study of serotonin neuron development in the rat: ascending pathways and terminal fields. Brain Res Bull 8:389-430. CrossRef Medline

Livesey FJ, Hunt SP (1997) Netrin and netrin receptor expression in the embryonic mammalian nervous system suggests roles in retinal, striatal, nigral, and cerebellar development. Mol Cell Neurosci 8:417-429. CrossRef Medline

Lundquist EA, Reddien PW, Hartwieg E, Horvitz HR, Bargmann CI (2001) Three C. elegans Rac proteins and several alternative Rac regulators control axon guidance, cell migration and apoptotic cell phagocytosis. Development 128:4475-4488. Medline

Manitt C, Colicos MA, Thompson KM, Rousselle E, Peterson AC, Kennedy TE (2001) Widespread expression of netrin-1 by neurons and oligodendrocytes in the adult mammalian spinal cord. J Neurosci 21:3911-3922. Medline

Manitt C, Nikolakopoulou AM, Almario DR, Nguyen SA, Cohen-Cory S (2009) Netrin participates in the development of retinotectal synaptic connectivity by modulating axon arborization and synapse formation in the developing brain. J Neurosci 29:11065-11077. CrossRef Medline

Manitt C, Mimee A, Eng C, Pokinko M, Stroh T, Cooper HM, Kolb B, Flores C (2011) The netrin receptor DCC is required in the pubertal organization of mesocortical dopamine circuitry. J Neurosci 31:8381-8394. CrossRef Medline

McConnell SK, Ghosh A, Shatz CJ (1989) Subplate neurons pioneer the first axon pathway from the cerebral cortex. Science 245:978-982. CrossRef Medline

Mello C, Fire A (1995) DNA transformation. Methods Cell Biol 48: 451-482. CrossRef Medline

Michael M, Vehlow A, Navarro C, Krause M (2010) c-Abl, Lamellipodin, and Ena/VASP proteins cooperate in dorsal ruffling of fibroblasts and axonal morphogenesis. Curr Biol 20:783-791. CrossRef Medline

Moukhles H, Bosler O, Bolam JP, Vallée A, Umbriaco D, Geffard M, Doucet G (1997) Quantitative and morphometric data indicate precise cellular interactions between serotonin terminals and postsynaptic targets in rat substantia nigra. Neuroscience 76:1159-1171. CrossRef Medline

Parent M, Wallman MJ, Descarries L (2010) Distribution and ultrastructural features of the serotonin innervation in rat and squirrel monkey subthalamic nucleus. Eur J Neurosci 31:1233-1242. CrossRef Medline

Park J, Knezevich PL, Wung W, O'Hanlon SN, Goyal A, Benedetti KL, BarsiRhyne BJ, Raman M, Mock N, Bremer M, Vanhoven MK (2011) A conserved juxtacrine signal regulates synaptic partner recognition in Caenorhabditis elegans. Neural Dev 6:28. CrossRef Medline

Quinn CC, Wadsworth WG (2008) Axon guidance: asymmetric signaling orients polarized outgrowth. Trends Cell Biol 18:597-603. CrossRef Medline

Rajasekharan S, Kennedy TE (2009) The netrin protein family. Genome Biol 10:239. CrossRef Medline

Ruthazer ES, Li J, Cline HT (2006) Stabilization of axon branch dynamics by synaptic maturation. J Neurosci 26:3594-3603. CrossRef Medline

Sawin ER, Ranganathan R, Horvitz HR (2000) C. elegans locomotory rate is modulated by the environment through a dopaminergic pathway and by experience through a serotonergic pathway. Neuron 26:619-631. CrossRef Medline

Seetharaman A, Selman G, Puckrin R, Barbier L, Wong E, D'Souza SA, Roy PJ (2011) MADD-4 is a secreted cue required for midline-oriented guidance in Caenorhabditis elegans. Dev Cell 21:669-680. CrossRef Medline

Serafini T, Kennedy TE, Galko MJ, Mirzayan C, Jessell TM, Tessier-Lavigne M (1994) The netrins define a family of axon outgrowth-promoting proteins homologous to C. elegans UNC-6. Cell 78:409-424. CrossRef Medline

Shatzmiller RA, Goldman JS, Simard-Emond L, Rymar V, Manitt C, Sadikot AF, Kennedy TE (2008) Graded expression of netrin-1 by specific neuronal subtypes in the adult mammalian striatum. Neuroscience 157:621-636. CrossRef Medline

Smith CJ, Watson JD, VanHoven MK, Colón-Ramos DA, Miller DM 3rd (2012) Netrin (UNC-6) mediates dendritic self-avoidance. Nat Neurosci 15:731-737. CrossRef Medline

Srinivasan K, Strickland P, Valdes A, Shin GC, Hinck L (2003) Netrin-1/ neogenin interaction stabilizes multipotent progenitor cap cells during mammary gland morphogenesis. Dev Cell 4:371-382. CrossRef Medline

Stavoe AK, Colón-Ramos DA (2012) Netrin instructs synaptic vesicle clustering through Rac GTPase, MIG-10, and the actin cytoskeleton. J Cell Biol 197:75-88. CrossRef Medline

Stavoe A, Nelson JC, Martínez-Velázquez LA, Klein M, Samuel AD, ColónRamos DA (2012) Synaptic vesicle clustering requires a distinct MIG10/Lamellipodin isoform and ABI-1 downstream from Netrin. Genes Dev 26:2206-2221. CrossRef Medline

Sze JY, Zhang S, Li J, Ruvkun G (2002) The C. elegans POU-domain transcription factor UNC-86 regulates the tph-1 tryptophan hydroxylase gene and neurite outgrowth in specific serotonergic neurons. Development 129:3901-3911. Medline

Timofeev K, Joly W, Hadjieconomou D, Salecker I (2012) Localized Netrins act as positional cues to control layer-specific targeting of photoreceptor axons in Drosophila. Neuron 75:80-93. CrossRef Medline

Vitalis T, Parnavelas JG (2003) The role of serotonin in early cortical development. Dev Neurosci 25:245-256. CrossRef Medline

Voutsinos B, Chouaf L, Mertens P, Ruiz-Flandes P, Joubert Y, Belin MF, Didier-Bazes M (1994) Tropism of serotonergic neurons towards glial targets in the rat ependyma. Neuroscience 59:663-672. CrossRef Medline

Wadsworth WG, Bhatt H, Hedgecock EM (1996) Neuroglia and pioneer neurons express UNC-6 to provide global and local netrin cues for guiding migrations in C. elegans. Neuron 16:35-46. CrossRef Medline

White JG, Southgate E, Thomson JN, Brenner S (1986) The structure of the nervous system of the nematode Caenorhabditis elegans. Philos Trans R Soc Lond B Biol Sci 314:1-340. CrossRef Medline

Wylie CJ, Hendricks TJ, Zhang B, Wang L, Lu P, Leahy P, Fox S, Maeno H, Deneris ES (2010) Distinct transcriptomes define rostral and caudal serotonin neurons. J Neurosci 30:670-684. CrossRef Medline

Xu B, Goldman JS, Rymar VV, Forget C, Lo PS, Bull SJ, Vereker E, Barker PA, Trudeau LE, Sadikot AF, Kennedy TE (2010) Critical roles for the netrin receptor deleted in colorectal cancer in dopaminergic neu- 
ronal precursor migration, axon guidance, and axon arborization. Neuroscience 169:932-949. CrossRef Medline

Yee KT, Simon HH, Tessier-Lavigne M, O'Leary DM (1999) Extension of long leading processes and neuronal migration in the mammalian brain directed by the chemoattractant netrin-1. Neuron 24:607-622. CrossRef Medline
Zallen JA, Kirch SA, Bargmann CI (1999) Genes required for axon pathfinding and extension in the C. elegans nerve ring. Development 126: 3679-3692. Medline

Zipkin ID, Kindt RM, Kenyon CJ (1997) Role of a new Rho family member in cell migration and axon guidance in C. elegans. Cell 90:883-894. CrossRef Medline 